\title{
Reacción en cadena de la polimerasa para la detección rápida y determinación del serotipo de virus del dengue en muestras clínicas
}

\author{
Delfina Rosario, ${ }^{1}$ Mayling Álvarez, ${ }^{1}$ Javier Díaz, ${ }^{2}$ \\ Rodolfo Contreras, ${ }^{3}$ Rosmari Rodríguez, ${ }^{1}$ \\ Susana Vázquez ${ }^{1}$ y María G. Guzmán ${ }^{1}$
}

RESUMEN El trabajo que aquí se presenta describe las ventajas de usar la reacción en cadena de la polimerasa con transcriptasa inversa (RCP-TI) para detectar e identificar con rapidez virus del dengue en muestras clínicas. Se sometieron directamente a RCP-TI 27 muestras obtenidas de pacientes con fiebre de dengue y fiebre hemorrágica de dengue durante epidemias en Colombia, Nicaragua y Panamá. El ADN de cadena doble obtenido con la RCP-TI se identificó mediante una segunda amplificación (RCP de anidación) utilizando cebadores específicos para cada tipo de virus, aislamiento vírico e inmunofluorescencia indirecta (IFI) y con electroinmunoensayo enzimático detector de anticuerpos IgM contra el virus del dengue. El genoma vírico amplificado se detectó e identificó en un máximo de 8 horas. Los parámetros calculados para hacer el diagnóstico por RCP-TI, usando el aislamiento vírico y la IFI como estándar de oro, fueron una sensibilidad de 100\%; una especificidad de $78 \%$; un valor predictivo positivo de $69 \%$ y un valor predictivo negativo de $100 \%$. Cabe notar que dos de los especímenes que dieron resultados positivos a la prueba de RCP-TI anidada y negativos al aislamiento vírico mostraron anticuerpos específicos de tipo IgM. Los resultados de la RCPTI en general mostraron una estrecha concordancia con los del aislamiento vírico, lo cual sugiere que la RCP es un procedimiento que facilita enormemente el diagnóstico rápido y temprano del dengue.

La fiebre del dengue (FD) y la forma grave de la enfermedad, conocida por

\footnotetext{
1 Instituto de Medicina Tropical Pedro Kourí, La Habana, Cuba. Toda correspondencia debe dirigirse a Delfina Rosario a la siguiente dirección postal: Instituto de Medicina Tropical Pedro Kourí, Apartado 601, Marianao 13, La Habana, Cuba. Teléfonos: 53-7-204910 al 29 y 53-7-336051. Fax: 53-7-215957 y 53-7-336051.

2 Universidad de Antioquia, Facultad de Medicina, Medellín, Colombia.

3 Centro Conmemorativo Gorgas, Ciudad de Panamá, Panamá.
}

fiebre hemorrágica del dengue (FHD) o síndrome de choque por dengue (SCD) y producida por cuatro serotipos distintos de virus (1, 2, 3 y 4), son un problema de salud importante en países tropicales $(1,2)$. En los últimos 20 años, los virus transmitidos por artrópodos han surgido de nuevo como causa importante de enfermedad en seres humanos. Durante este período, la frecuencia de epidemias por FD ha aumentado enormemente en numerosos países americanos que no habían notificado casos de dengue en 50 años o más, y se han producido casos de FHD en zonas nuevas con una alta incidencia de dengue, tales como Brasil, Colombia, El Salvador, México, Nicaragua y Puerto Rico. La expansión territorial de las epidemias de dengue en los años ochenta afectó a América del Sur, América del Norte y Centroamé- 
rica, África, China y Australia, y se cree que continuará en ciertos lugares infestados con Aedes aegypti (3), de los cuales son ejemplos varios países del centro y sur del África, estados del sur del Brasil, Paraguay y el norte de Argentina. Según la OMS, 2000 millones de personas en el mundo se encuentran en riesgo y 10 a 60 millones de casos ocurren cada año, a un costo elevadísimo si se suman las medidas de control, la atención médica y las horas laborales perdidas.

De 1980 a 1994 aumentaron notablemente el territorio afectado y la incidencia de dengue en las Américas. Durante este período toda actividad por dengue en la Región se debió a los serotipos 1, 2 y 4 . No obstante, en octubre de 1994 el serotipo 3 volvió a aparecer en la Región (4-6) y en abril del mismo año la OPS declaró un estado de alerta en los países y recomendó reforzar la vigilancia del virus y las medidas de control $(3,6)$.

El departamento de virología del Instituto de Medicina Tropical Pedro Kourí en La Habana, Cuba, que es un Centro Colaborador de la OPS/OMS en Materia de Enfermedades Víricas, suele recibir muestras de suero de muchos países de la Región para el diagnóstico de dengue o su confirmación. Las técnicas estándares que se utilizan en el Instituto son el aislamiento del virus en cultivos celulares y el inmunoensayo enzimático (ELISA) de captura para la detección de IgM. En los últimos años también se ha usado el método de la reacción en cadena de la polimerasa con transcriptasa inversa (RCP-TI) para detectar la presencia del genoma del virus del dengue (7-13). En el presente estudio se detectaron fragmentos del genoma de este virus mediante el uso de una RCP-TI de un solo paso. La identificación del serotipo se hizo con una RCP de anidación y una serie de cebadores antisentido específicos para cada uno de los cuatro serotipos del virus del dengue. Con estos cebadores se obtuvieron productos de la RCP de distintos tamaños que se pudieron identificar con facilidad mediante electroforesis en gel de agarosa. Por ser el dengue una enfermedad fe- bril aguda, su diagnóstico temprano podría mejorar la eficacia de su tratamiento y facilitar la aplicación de medidas para el control del vector. Estos motivos nos llevaron a evaluar las posibilidades de usar la RCP-TI para el diagnóstico temprano y rápido de la infección vírica usando muestras de suero recolectadas en Colombia, Nicaragua y Panamá. 4

En el presente estudio se detectaron fragmentos del genoma del virus del dengue mediante el uso de una RCPTI de un solo paso. La identificación de serotipos se hizo con una RCP de anidación y una serie de cebadores antisentido específicos para cada uno de los cuatro serotipos del virus del dengue. Con estos cebadores se obtuvieron productos de la RCP de distintos tamaños que se pudieron identificar con facilidad mediante electroforesis en gel de agarosa. Los resultados de este estudio sugieren que esta prueba es lo suficientemente confiable para poder aplicarse en el diagnóstico temprano del dengue en varios países de la Región y en estudios de epidemiología molecular.

\section{MATERIALES Y MÉTODOS}

\section{Sueros de pacientes}

Las 27 muestras de suero usadas en este estudio se recogieron durante la fase aguda de la enfermedad ( 24 horas a 5 días después de los primeros síntomas) de pacientes colombianos (15 muestras), nicaragüenses (10 muestras) y panameños (dos muestras) que entre octubre de 1994 y julio de 1995 recibieron un diagnóstico clínico de FD o de FHD. Las muestras de suero procedentes de Colombia y Panamá se sometieron a pruebas en cultivos celu-

\footnotetext{
4 Esto se hizo por recomendación de funcionarios de la OPS durante el Curso Internacional sobre el Dengue y la Fiebre Hemorrágica del Dengue en las Américas , que tuvo lugar en el Instituto de Medicina Tropical Pedro Kourí en 1995.
}

lares en sus respectivos países y posteriormente se enviaron a Cuba, donde se almacenaron a $-70{ }^{\circ} \mathrm{C}$ hasta ser estudiadas en el Instituto de Medicina Tropical Pedro Kourí. El tiempo de almacenamiento varió de 15 días a 6 meses, pero en nuestra experiencia las muestras almacenadas a una temperatura estable de $-70{ }^{\circ} \mathrm{C}$ o menos han sido útiles durante años, tanto para el diagnóstico por aislamiento en cultivo celular como por RCP-TI. Las muestras procedentes de Nicaragua se enviaron en refrigeración a fin de mantener la viabilidad de los virus y al llegar a Cuba se sometieron a análisis en cultivos celulares. Todas las muestras se sometieron a ELISA de captura para la detección de $\operatorname{IgM}(14)$, técnica que se inventó en el laboratorio de referencia del Instituto para la detección de arbovirus (JL Pelegrino, comunicación personal).

\section{Cultivos y medios celulares}

Una línea celular del clono C6/36 de mosquitos Aedes albopictus se cultivó a $28^{\circ} \mathrm{C}$ en el medio mínimo esencial (MME) de Eagle suplementado con suero fetal bovino (SFB) al 10\% y $0,2 \mathrm{mM}$ de aminoácidos no esenciales. Para el medio de mantenimiento se redujo el SFB a una concentración de 2\%. El medio de mantenimiento se usó después de inocular las células con los especímenes de suero para aislar el virus.

\section{Cepas de virus del dengue}

En el presente estudio se usaron las siguientes cepas prototípicas de virus del dengue: cepa cubana de virus del dengue tipo 1 (DEN-1) D1-77 (15); cepa cubana de virus del dengue tipo 2 (DEN-2) A15 obtenida durante la epidemia de 1981 (16); cepa nicaragüense de virus del dengue tipo 3 (DEN-3) NIC-24 obtenida durante la epidemia de 1994 (4), y cepa H241 de virus del dengue tipo 4 (DEN-4). 


\section{Antisueros}

Se usaron para nuestro estudio los cuatro siguientes anticuerpos monoclonales específicos contra cada serotipo de virus del dengue: 15F3 (DEN1); 3H5 (DEN-2); $5 \mathrm{D} 4$ (DEN-3), y 1H10 (DEN-4). Estos fueron proporcionados en su totalidad por los Centros para el Control y la Prevención de Enfermedades, Atlanta, Georgia, EUA.

\section{Aislamiento, identificación y determinación de serotipos víricos mediante inmunofluorescencia indirecta}

La capa monocelular del clono C6/36 fue inoculada con $40 \mu \mathrm{L}$ de suero e incubada a $28{ }^{\circ} \mathrm{C}$ durante una hora. Después de la incubación se le añadieron $2 \mathrm{~mL}$ de medio de mantenimiento a cada tubo de cultivo, que se volvió a incubar a $28{ }^{\circ} \mathrm{C}$ durante 10 días. Los cultivos celulares se sometieron a inmunofluorescencia indirecta (IFI) para detectar la presencia de virus del dengue $(17,18)$, usando líquido ascítico policlonal contra el virus tipo 3 (que a una dilución baja, como de 1:10, reacciona con los cuatro serotipos de virus del dengue). Una vez observada la fluorescencia específica, se procedió a identificar los serotipos víricos con anticuerpos monoclonales. En los casos en que no se produjo inmunofluorescencia, se efectuó una segunda pasada por el mismo cultivo celular y se repitió el tamizaje.

\section{Extracción del ácido ribonucleico}

El ácido ribonucleico (ARN) del virus se aisló mediante una modificación del procedimiento descrito por Chomczynski y Sacchi (19). Básicamente, $200 \mu \mathrm{L}$ de cada muestra de suero o de líquido sobrenadante de células infectadas se mezclaron con un volumen idéntico de amortiguador lítico de isotiocianato de guanidina a base de $8 \mathrm{M}$ de isotiocianato de guani-

CUADRO 1. Cebadores de oligonucleótidos usados para amplificar los virus del dengue y determinar su serotipo

\begin{tabular}{llc}
\hline Cebador & \multicolumn{1}{c}{ Secuencia de bases } & Longitud del ADN producido \\
\hline D1 & 5' TCAATATGCTGAAACGCGCGAGAAACCG 3' & $511 \mathrm{pb}^{\mathrm{a}}$ \\
D2 & 5' TTGCACCAACAGTCAATGTCTTCAGGTTC 3' & $511 \mathrm{pb}$ \\
TS1 & 5' CGTCTCAGTGATCCGGGGG 3' & $482 \mathrm{pb}$ (D1 y TS1) \\
TS2 & 5' CGCCACAAGGGCCATGAACAG 3' & $119 \mathrm{pb}$ (D1 y TS2) \\
TS3 & 5' TAACATCATCATGAGACAGAGC 3' & $290 \mathrm{pb}$ (D1 y TS3) \\
TS4 & 5' CTCTGTTGTCTTAAACAAGAGA 3' & $392 \mathrm{pb}$ (D1 y TS4) \\
\hline
\end{tabular}

${ }^{\mathrm{a}} \mathrm{pb}=$ pares de bases.

dina, $50 \mathrm{mM}$ de citrato de sodio, $100 \mathrm{mM}$ de 2-mercaptoetanol, 1\% de sarcosil y $1 \mu \mathrm{g} / \mathrm{mL}$ de ARN de transferencia obtenido de levadura.

Para extraer el ARN de las células infectadas, utilizamos amortiguador lítico diluido a la mitad de su concentración normal. Posteriormente a la solución se le añadieron los siguientes consecutivamente (las partes se dan en relación con el volumen final de la muestra más el amortiguador lítico): $1 / 10$ de acetato sódico $2 \mathrm{M}$ (a un pH de 4); un volumen idéntico de fenol balanceado con agua, y 2/10 de cloroformo. Esta mezcla se centrifugó a 16000 rotaciones/minuto durante 15 minutos y la fase acuosa se recogió y combinó con un volumen idéntico de isopropanolol para precipitar el ARN. Después de la centrifugación, el botón de ARN se enjuagó con $200 \mu \mathrm{L}$ de etanol al $75 \%$ y se disolvió en $20 \mu \mathrm{L}$ de agua.

\section{Reacción en cadena de la polimerasa con transcriptasa inversa}

Se aplicó la técnica de la reacción en cadena de la polimerasa con transcriptasa inversa (RCP-TI) descrita por Lanciotti et al. (20). Se añadieron $10 \mu \mathrm{L}$ del ARN vírico investigado a $90 \mu \mathrm{L}$ de una mezcla de RCP-TI con los siguientes componentes: $50 \mathrm{mM}$ de $\mathrm{KCl}, 10 \mathrm{mM}$ de medio Tris (a un pH de 8,5), 1,5 mM de $\mathrm{MgCl}_{2}, 0,01 \%$ de gelatina, $200 \mu \mathrm{M}$ de cada uno de cuatro desoxinucleótidos fosfatados, $5 \mathrm{mM}$ de ditiotreitol, 50 pmol de cada uno de dos cebado- $\operatorname{res}^{5}$ (D1 y D2, cuadro 1) con un grado máximo de correspondencia nucleotídica con los cuatro serotipos víricos, $10 \mathrm{U}$ de TI-AMV (nombre comercial del reactivo de la Boehringer que consiste en virus de la micoblastosis aviaria y transcriptasa inversa) y 2,5 U de polimerasa de ADN Taq (Boehringer). Se dejó que procedieran las reacciones en un termociclador (marca MJ Research, Inc., Watertown, Massachusetts, EUA) programado para una incubación de 30 minutos a $42{ }^{\circ} \mathrm{C}$ seguida de 35 ciclos de desnaturalización (a $94{ }^{\circ} \mathrm{C}$ durante 30 segundos), templado (annealing) con el cebador (a $55^{\circ} \mathrm{C}$ durante 1 minuto) y extensión (a $72{ }^{\circ} \mathrm{C}$ durante 2 minutos).

\section{Determinación del serotipo vírico con una segunda amplificación con cebadores específicos para cada serotipo (RCP de anidación)}

Se inició una segunda reacción amplificadora con $1 \mu \mathrm{L}$ del producto de la primera RCP. La mezcla usada para la segunda reacción tenía todos los componentes usados en la primera, con las siguientes excepciones: se reemplazó el cebador D2 con cebadores TS1, TS2, TS3 y TS4 (cuadro 1) para serotipos víricos específicos y se eliminaron el ditiotreitol y la TI. Las muestras se so-

\footnotetext{
Todos los cebadores usados en este estudio fueron proporcionados por cortesía de Eva Harris de la Universidad de San Francisco, San Francisco, California, EUA.
} 
metieron a 26 ciclos de desnaturalización (a $94{ }^{\circ} \mathrm{C}$ durante 30 segundos), templado con el cebador $\left(\mathrm{a} 55^{\circ} \mathrm{C}\right.$ durante 1 minuto) y extensión con el cebador (a $72{ }^{\circ} \mathrm{C}$ durante 2 minutos). Una porción de $10 \mu \mathrm{L}$ del producto de la reacción se sometió a electroforesis en gel de agarosa al 2,5\% usando un amortiguador a base de $0,4 \mathrm{M}$ de medio Tris, 0,5 M de acetato sódico y 0,01 M de ácido etilendiamín tetracético. Debido a la posición en que actúa cada uno de los cebadores para los distintos serotipos de virus del dengue, el tamaño de la banda de ADN obtenida fue distintiva para cada serotipo de virus.

\section{RESULTADOS}

Hemos aplicado la RCP de anidación a 27 especímenes de suero recolectados de pacientes con un diagnóstico clínico de FD (25 pacientes) o FHD (2 pacientes) durante la fase aguda de la enfermedad (de 24 horas a 5 días después de los primeros síntomas). Se aislaron virus del dengue por cultivo celular de nueve de las muestras y se confirmó su serotipo mediante IFI. Dos de estos sueros contenían anticuerpos IgM contra el virus del dengue y hubo que volver a pasar las muestras por el mismo sistema de cultivo celular antes de poder identificar el virus con los anticuerpos monoclonales. De los 18 sueros que salieron negativos al cultivo de virus, nueve mostraron anticuerpos IgM.

$\mathrm{Al}$ aplicarse la RCP-TI y la RCP de anidación, el ARN de virus del dengue se detectó en el suero de los nueve pacientes en quienes se había aislado el virus y en el de cuatro de los 18 pacientes con cultivos víricos negativos. Esto da una correlación de 85,1\% entre los resultados del cultivo celular y los de la RCP-TI. El serotipo presente en los 13 especímenes positivos en la RCP se determinó con RCP de anidación usando cebadores específicos para cada serotipo y se confirmó volviendo a someter las muestras originales por segunda vez a RCP-TI y RCP de anidación. Cuatro muestras resultaron posi- tivas al serotipo 1 (una de Panamá y tres de Colombia), tres al serotipo 2 (todas de Colombia) y seis al serotipo 3 (todas de Nicaragua). La identificación de los serotipos mostró concordancia completa con los resultados de la IFI.

Las 27 muestras de suero se sometieron a ELISA de captura para IgM con especificidad contra el virus del dengue y 15 sueros mostraron anticuerpos IgM contra este virus. Solamente cuatro de ellos fueron positivos a la RCP de anidación. Si el aislamiento en cultivo celular se toma como "estándar de oro", la sensibilidad de la RCP fue de $100 \%$, su especificidad de $77 \%$, su valor predictivo positivo (VPP) de $69,2 \%$ y su valor predictivo negativo (VPN) de $100 \%$.

\section{DISCUSIÓN}

A pesar de que el método de RCP ideado por Lanciotti et al. en 1992 (20) ha sido probado previamente en distintos lugares y momentos con distintas cepas de virus del dengue obtenidas de muestras de sueros virémicos y también con virus prototípicos estándar, hace falta evaluar más a fondo su utilidad, especificidad y sensibilidad para detectar e identificar los serotipos de virus del dengue presentes en muestras tomadas de pacientes.

Para poder identificar con exactitud los serotipos de virus del dengue aplicando la RCP de anidación con la mezcla de cebadores específicos se necesita únicamente someter el producto amplificado a electroforesis en gel de agarosa, mientras que el protocolo de hibridación exige que se rotulen, purifiquen y estandaricen sondas que suelen ser difíciles de reproducir (7).

En nuestro estudio notificamos una buena correlación $(85,1 \%)$ con los resultados del cultivo celular estandarizado, pese a que este procedimiento se llevó a cabo en tres laboratorios distintos de Colombia, Cuba y Panamá.

Debido al peligro de contaminación cruzada con RCP-TI durante la libre manipulación del producto amplificado, se han observado en ocasiones resultados positivos falsos al aplicar la técnica de la $\operatorname{RCP}(7,8,21,22)$. Se evitó este problema mediante una serie de precauciones (la separación física de la manipulación antes y después de la $\mathrm{RCP}$, la irradiación con luz ultravioleta de las mezclas usadas en las reacciones, y la inclusión de varias muestras sin ADN para llevar un control cuidadoso durante cada ensayo).

Las 15 muestras positivas a IgM específica contra virus del dengue demuestran que es posible detectar anticuerpos antivíricos incluso al final de la fase aguda de la enfermedad.

Se pudo amplificar el ADN complementario al ARN vírico en cuatro muestras que salieron negativas al cultivo de virus. Es posible que en dos sueros con anticuerpos IgM los inmunocomplejos hayan inhibido la susceptibilidad de las células a la infección vírica. Otras razones que podrían explicar los resultados negativos falsos son la presencia de títulos víricos bajos y la conservación de la muestra a una temperatura inadecuada antes de la prueba. Nuestros resultados de sensibilidad, especificidad, VPP y VPN se asemejan a los notificados en otros trabajos publicados (7).

Estos datos ponen de relieve la mayor sensibilidad de la RCP, y particularmente de la RCP de anidación, cuando se compara con la de otros métodos. Esta prueba puede hacerse en 8 horas y usarse para complementar, y en algunos casos sustituir, a las técnicas establecidas en muchos países de la Región. Otra posible aplicación que debe explorarse es la de usar la RCP-TI para detectar e identificar serotipos del virus del dengue en familias de mosquitos capturados al aire libre durante actividades de vigilancia entomológica. La técnica básica de amplificar directamente el ARN hasta convertirlo en ADN de doble cadena por acción de la transcriptasa inversa puede aplicarse para amplificar una región extensa del genoma con objeto de secuenciarla rápidamente $\mathrm{o}$ de hacer análisis de restricción del mismo producto amplificado, procedimiento que resulta más fácil y que tiene utilidad para hacer análisis epidemiológicos y estudios de evolución (23). 
1. Halstead SB. Dengue hemorrhagic fever: a public health problem and a field for research. Bull World Health Organ 1980;58:1-21.

2. Halstead SB. Global epidemiology of dengue hemorrhagic fever. Southeast Asian J Trop Med Public Health 1990;21:636-641.

3. Monath TP. Dengue: the risk to developed and developing countries. Proc Natl Acad Sci USA 1994;91:2395-2400.

4. Guzmán MG, Vázquez S, Martínez E, Álvarez M, Rodríguez R, Kourí G, et al. Dengue in Nicaragua, 1994: reintroduction of serotype 3 in the Americas. Bull Pan Am Health Organ 1996;121:102-110

5. Centers for Disease Control and Prevention. Dengue type 3 infection: Nicaragua and Panama, October-November, 1994. MMWR 1995;44 (Jan 20):2.

6. Pinheiro FP. Situación del dengue y el dengue hemorrágico en las Américas. En: Memorias del Curso Internacional de Dengue y Dengue Hemorrágico en las Américas. La Habana: Instituto "Pedro Kourí"; 1995. pp. 3-14.

7. Deubel V, Laille M, Hugnot JP, Chungue E, Guesdon J, Drouet MT, et al. Identification of dengue sequences by genomic amplification: rapid diagnosis of dengue virus serotypes in peripheral blood. J Virol Methods 1990;30: 41-54.

8. Eldadah ZA, Aseher DM, Godec MS, Pomeroy KL, Goldfarb LG, Feinstone FM, et al. Detection of flavivirus by reverse transcriptasepolymerase chain reaction. J Med Virol 1991; 33:260-267.

9. Henchal EA, Polo SL, Vordan V, Yaemsiri C, Innis $\mathrm{B}$, Hoke $\mathrm{CH}$. Sensitivity and specificity of a universal primer set for the rapid diagno- sis of dengue virus infections by polymerase chain reaction and nucleic acid hybridization. Am J Trop Med Hyg 1991;45:418-428.

10. Laille MV, Deubel V, Sainte-Marie FF. Demonstration of concurrent dengue 1 and dengue 3 infection in six patients by the polymerase chain reaction. J Med Virol 1991;34:51-54.

11. Maneekarn N, Morita K, Tanaka M, Igarashi A, Usawattanakul W, Sinsanthana V, et al. Application of polymerase chain reaction for identification of dengue viruses isolated from patient sera. Microbiol Immunol 1993;37:41-47.

12. Morita K, Tanaka M, Igarashi A. Rapid identification of dengue virus serotypes by using polymerase chain reaction. J Clin Micobiol 1991;29:2107-2110.

13. Morita K, Maemoto T, Honda S, Onishi K, Murata M, Tanaka M, et al. Rapid detection of virus genome from imported dengue fever and dengue hemorrhagic fever patients by direct polymerase chain reaction. J Med Virol 1994;44:54-58.

14. Bundo K, Igarashi A. Antibody-capture ELISA for detection of immunoglobulin $\mathrm{M}$ antibodies in sera from Japanese encephalitis and dengue hemorrhagic fever patients. Virol Methods 1985;11:15-22.

15. Mas P. Dengue fever in Cuba in 1977: some laboratory aspects. En: Pan American Health Organization. Dengue in the Caribbean, 1977. Washington, DC: PAHO; 1979. pp. 40-43. (Scientific Publication 375).

16. Kouri G, Mas P, Guzman MG, Soler M, Goyenechea A, Morier L. Dengue hemorrhagic fever in Cuba, 1981: rapid diagnosis of the etiologic agent. Bull Pan Am Health Organ 1982;93:414-420.
17. Henchal EA, Gentry MK, McCown JM, Brandt WE. Dengue virus-specific and flavivirus group determinants identified with monoclonal antibodies by indirect immunofluorescence. Am J Trop Med Hyg 1982;31:830-836.

18. Henchal EA, McCown JM, Seguin MC, Gentry MK, Brandt WE. Rapid identification of dengue virus isolates by using monoclonal antibodies in an indirect immunofluorescence assay. Am J Trop Med Hyg 1983;32:164-169.

19. Chomczynski P, Sacchi N. Single-step method of RNA isolation by acid guanidinium thiocyanate-phenol-chloroform extraction. Anal Biochem 1987;162:156-159.

20. Lanciotti RS, Calisher CH, Gubler DJ, Chang GJ, Vordan V. Rapid detection and typing of dengue viruses from clinical samples by using reverse transcriptase-polymerase chain reaction. J Clin Microbiol 1992;30:545-551.

21. Belák S, Ballagi-Pordány A. Experiences on the application of polymerase chain reaction in a diagnostic laboratory. Mol Cell Probes 1993;7:241-248

22. Stoker NG. The polymerase chain reaction and infectious diseases: hopes and realities. Trans R Soc Trop Med Hyg 1990;84:755-756.

23. Lanciotti RS, Lewis JG, Gubler DJ, Trent DW. Molecular evolution and epidemiology of dengue-3 viruses. J Gen Virol 1994;75:65-75.

Manuscrito recibido el 30 de abril de 1997 y aceptado para publicación, en versión revisada, el 21 de abril de 1998.
ABSTRACT

\section{Polymerase chain reaction for rapid detection and serotyping of dengue viruses in clinical samples}

This study describes the benefits of using reverse transcriptase polymerase chain reaction (RT-PCR) for the rapid detection and typing of dengue virus in clinical samples. Twenty-seven serum specimens from patients with dengue fever and dengue hemorrhagic fever in Colombia, Nicaragua, and Panama were directly subjected to RT-PCR for the detection of dengue virus. The resulting double-stranded DNA product was typed by a second round of PCR amplification (nested PCR) with typespecific primers, viral culture/indirect immunofluorescence (IIF), and enzyme-linked electroimmunoassay for $\operatorname{IgM}$ anti-dengue antibodies. The amplified virus genome was detected and typed within 8 hours. Nested RT-PCR, using viral culture and IIF as the gold standard, showed $100 \%$ sensitivity; $78 \%$ specificity; $69 \%$ positive predictive value, and $100 \%$ negative predictive value. It is noteworthy that two of the specimens whose results were positive with nested RT-PCR and negative with viral culture showed specific IgM antibodies. The results of the RT-PCR were in close agreement with those obtained through viral culture. This suggests PCR can greatly facilitate the rapid and early diagnosis of dengue infection. 